\title{
Computational Modeling of the Probability of Destructions in Total Joint Endoprosthesis Ceramic Heads using Weibull's Theory
}

\section{Přemysl Janíček (CZ)}

\section{Vladimír Fuis (CZ)}

Michal Málek (CZ)

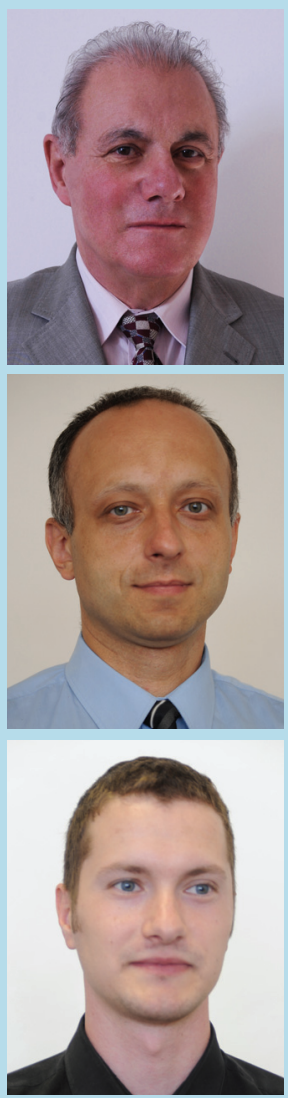

\section{BIOGRAPHICAL NOTES}

prof. Ing. Přemysl. Janíček, DrSc., born on the 1st December 1935 in Sastin-Straze, Slovakia, graduated in 1959 at the Faculty of Mechanical Engineering, Technical University Bratislava, Slovakia. Now he is professor at the Institute of Solid Mechanics, Mechatronics and Biomechanics, Faculty of Mechanical Engineering, Brno University of Technology, Brno, Czech Republic. His field of study covers mechanics of solid bodies, human biomechanics, theory of system, theory of modelling, theory of experiment, theory of statistics, behavior of materials. He is chairman of the Engineering Mechanics Branch Council, deputy chairman of the Committee of the Czech Society for Biomechanics, head of the society's Moravian branch, member of the scientific board of the Faculty of Education of the Masaryk University in Brno, as well as member of editorial boards of several scientific journals. His publication activity contains 121 scientific articles in journals, 86 papers on conferences and 19 reports of grant projects. He is co-author of the publication "Computational Models in Engineering Practice" and author of the "Systematic Encyclopedia of Selected Disciplines for Engineers".

Ing. Vladimír Fuis, PhD., born on the 13th October 1970 in Brno, Czech Republic, graduated in 1994 at the Faculty of Mechanical Engineering, Brno University of Technology. Now he is head the - Now he is head of the Centre of Mechatronics at the Centre of Mechatronics - Institute of Thermomechanics, Academy of Science of the Czech Republic. His professional activity is oriented into the area of computational modelling in the field of mechanics of solids, micro and macro shape deviations of the hip implant contact area, reliability of ceramic head of total hip replacement, computational modelling of magnetic drives, modelling of degradation processes, residual stress of heat spray coatings of Eucor ceramics, stability of resistors of traction vehicles, and other. He was awarded by the "Dr Špaček's Biomechanics Award" and "Dean's Award".

Ing. Michal Málek, born on 1985, graduated at the Faculty of Mechanical Engineering, Brno University of Technology, with the diploma work "Reliability analysis of the hip point endoprosthesis ceramic head. Now he is working in the company Siemens Electric Machines, Ltd. Professionally is oriented in area of solid mechanics, computational modelling, FEM, reliability, design of the electric motors. 


\section{KEY WORDS}

Computational Modeling, Ceramic Head, in Vivo Destructions, Hip Joint Endoprosthesis, Probabily of Rupture, Shape Deviations of the Contact Areas, Weibull Theory

\section{ABSTRACT}

This report deals with the issue of finding causes of ceramic heads destructions in total joint endoprostheses. It has been identified that the head fractures were caused by improper mutual geometry tolerances in the taper joint between the ceramic head and the metal stem. This fact was revealed by the results of deformation-stress analyses of heads with various geometric imperfections in the taper contact with the stem using FEM. The issue was further elaborated in the sense of determination of probability of head destruction by existing shape macro-deviations of the taper contact surface of the head and stem, such as varying taper ratio and ovality, taking into consideration micro-roughness from splinter machining of the surfaces of the internal taper of head and the external taper of stem. To estimate the probability of head destruction, we used weakest link Weibull's theory.

\section{INTRODUCTION}

Functioning of every joint in human organism is ensured by the kinematic pair between two adjoining bones. Loss of the functionality of the kinematic pair in the form of pathologic changes to contact surfaces means that the joint loses its functionality. The most frequent cause of these changes consists in degradation changes in cartilages, sometimes leading to entire disappearance. The joint function can be re-established by surgery - implanting of the total endoprosthesis (currently mostly hip, knee and elbow).

Total endoprostheses of large joints are functional and structural "copies" of real joints. Their structure consists of two elements (counterparts) with the "same" shape as the terminations of the two adjoining bones, into which they are inserted. However, total endoprostheses are not the final solution to the pathologic joint condition, because their life if limited. It is interesting that the cause of the shortened life consists primarily in degradation processes on the contact surfaces, too. The surfaces undergo abrasion that migrates to bone tissues that subsequently degenerate so much that the endoprosthesis elements fixed in bones become loose. The wear from steel elements causes the socalled metal disease, while wear from high-molecular polyethylene cause polyethylene disease [5]. This was the reason why the contact elements in endoprostheses began to be made from ceramic materials with low abrasion. However, this benefit has its disadvantages. Ceramics are less "flexible" than steel (steel flexibility module is $210 \mathrm{GPa}$, ceramics approx. $380 \mathrm{GPa}$ ) and ceramics is very fragile. Under certain conditions (impact loading, concentrated stress in bodies) it becomes damaged by uncontrollable fragile fracture. This brings us to the issue being solved by this report.

\section{PROBLEM SITUATION}

According to the theory of systems [18], a problematic situation is such non-standard condition of any entity that requires a change, for subjective or objective reasons. The change is brought about by solving of the problem and it represents substantial facts formulated from the problem situation. Problem solving requires realization of information-based, creative, evaluating, decision-making and executive activities. This is how the problem differs from solving of any other situations.

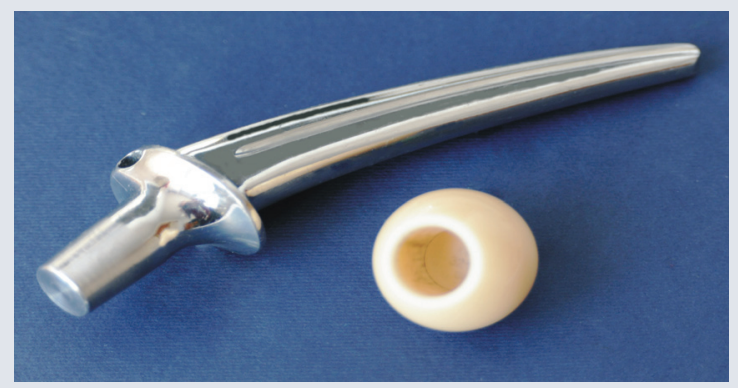

Fig. 1 Stem and ceramic head of the total hip endoprosthesis

What was the problem situation solved in this report? At one time, ceramic heads in the total joint endoprostheses with metal stems to which ceramic heads were inserted by "self-locking taper connection" began to degrade (destructions in vivo [15]) in many people (Fig. 1). These began, in substantial numbers, to break by fractures similar to an orange broken up to slices (Fig. 2). The fractures occurred abroad as well as in our hospitals. Patients blamed doctors. However, the doctors were sure of their innocence and therefore they asked the Institute of 
Solid Mechanics, Mechatronics and Biomechanics (ISMMB), Faculty of mechanical engineering, Brno University of Technology, which has been studying clinical biomechanical issues since 1985, to help deal with the situation.

Biomechanicians in the institute began to investigate what caused the fractures of ceramic heads. As any ceramics, heads made of aluminum oxide $\left(\mathrm{Al}_{2} \mathrm{O}_{3}\right)$ ceramics behave in a fragile manner. It means that under certain conditions (stress on heads, quality of contact surfaces on the internal head taper and external stem taper, physical property of head ceramics) heads will be disturbed by fragile fractures with some probability. To assess the limit condition of material coherence by fragile fracture requires knowledge about the stress on the head in practical (physiological) conditions (a person walking with an implanted endoprosthesis, studied by prof. Bergmann [3], [4]) and information on physical properties of ceramics used to make the heads [16].

Finding a cause for fragile head fractures means, in the sense of the theory of systems, solving of an indirect problem. It is a problem whose consequences are known (head fractures), but we need to find its causes. Since heads were fractured in people who did "normal walking", not people who engaged in sports (volleyball, basketball, soccer, skiing, running) we excluded overstressing of the total endoprosthesis as the cause of the fractures. Our research has focused on shape deviations of the geometry of internal and external taper (various degree of taper, ovality, large micro-roughness on taper surfaces). Due to the complexity of the stem and head shape (geometric imperfections on contact surfaces must be taken into account) and complexity of ceramics behavior (stochastic of the ceramics structure must be taken into account and its fractures must be assessed using probability approaches), mathematical analytical methods cannot be used at all. Inverse numeric methods cannot be used either, because they are instable.

We must therefore proceed "forwards" in a sense that we define deformation-stress conditions of the head for various stress values and various geometric imperfections of contact surfaces. The acquired results then become input values for algorithms of stochastic assessment of heads damage probability.
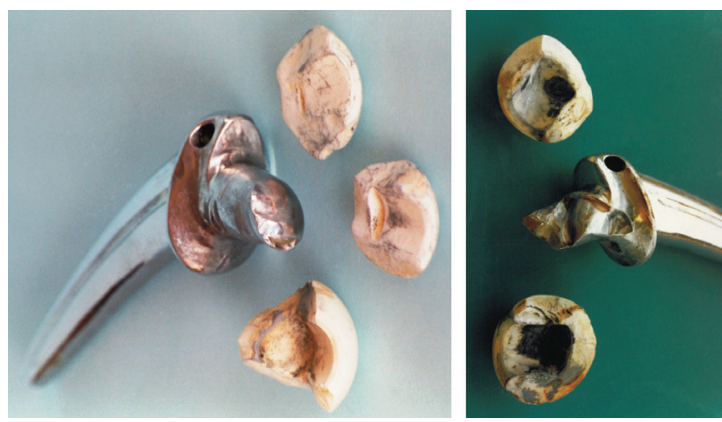

Fig. 2 Destructed ceramic heads of the total hip joint endoprostheses

\section{ASSESSMENT OF THE RELIABILITY FROM OBJECTS MADE OF CERAMIC MATERIALS}

Fracturing of metal materials in a fragile condition is assessed by fragile fracture based on the condition of fragile sthrength. It states that the limit condition of fragile sthrength occurs when reduced stress, corresponding to the condition at hand, equals the fragile sthrength limit. Such concept can be perceived as the first level of assessment of its fragile fracture for the ceramics.

Higher levels of assessment involve taking into account non-homogeneity of ceramics structure in the sense that it contains numerous micro-failures (pores, cavities and cracks) that increase susceptibility to fragile fracturing. For assessment of fracturing of ceramics cohesion we must use probability approach respecting stochastic division of micro-fractures in the ceramics body volume. This approach describes origination of the limit condition of fragile fracture the so-called "probability of destruction". This is a statistic approach to destruction of ceramics.

There are various statistic reliability approaches. One is the Weibull's weakest-link theory [21], based on a very simplified assumption that a reliabilityassessed ceramics body is perceived as a system consisting of many elements [20], [1], [6]. If in any elements of the body there originates a stress that causes, under existing physical properties of the ceramics, uncontrolled spreading of a fragile fracture in the element, it usually results in a fragile destruction to the entire body. The issue of ceramics body reliability in view of destruction of its integrity was thus converted to the determination of probability of destruction Pf regarding individual elements of the body.

Due to the accidental distribution of defects in 
the volume of bodies made of ceramic materials, physical properties of individual micro-volumes of these materials differ and thus various microvolumes have different real fragile sthrength. It is being proved that statistical distribution of the probability of ceramic materials destructions is of Weibull's type. More micro-volumes in the body increase probability that the body contains a "weak link", in which the fragile destruction is initiated. Probability of failure of ceramic bodies in the form of fragile destruction is the function of all microvolumes in the body with various stresses.

From the aforementioned facts, W. Weibull [21] deduced mathematical formulae governing the probability of destruction in ceramic bodies for various "stress levels" originating in bodies as a result of external load. In the simpler model, he considered only 1 -axis tensile stress, on the higher level he worked with real 3 -axis stress. The levels of stress modeling are briefly analyzed below.

\section{A. Weibull's model of destruction probability for a 1-axis tensile stress}

This model has been elaborated for two modifications of Weibull's theory: three-parametric (contains three ceramics material parameters) and two-parametric (with two parameters). The original Weibull's formulae for destruction probability Pf were deduced in integral shape [6]. Since stress, one of the input quantities in the Weibull's theory, is determined using the finite elements method, Weibull's formulae are quoted in the differential shape here.

Three-parametric Weibull's formula is as follows:

$P_{f}=1-e^{-\sum_{i=1}^{n}\left(\frac{\sigma_{i}-\sigma_{u}}{\sigma_{0}}\right)^{m} \Delta V_{i}}, \sigma_{i}>\sigma_{u}$

where

$n$ number of elements in the body,

$\sigma_{i}$ first principal stress in the i-th body element,

$\Delta V_{i}$ volume of the i-th body element,

$\sigma_{u}$ stress [MPa], under which material is not disrupted,

$\sigma_{0}$ normalized material sthrength $\left[\mathrm{MPa} \cdot \mathrm{m}^{3 / \mathrm{m}}\right.$ ] of the material volume unit,

$m$ Weibull's modulus

Notes: In defining of stress in the body using the finite elements method, the number of body elements $n$ equals to the number body discretion ele- ments discretization.

Quantities $\sigma_{u}, \sigma_{0,} m$ can be considered material properties of ceramics.

For two-parametric Weibull's approach, $\sigma_{u}=0$, which means that material destruction is possible for any tensile (positive) values of the first principal stress [6]. Two-parametric analysis is used more frequently, because it provides more conservative results than the three-parametric analysis. It is defined by the following formula:

$$
P_{f}=1-e^{-\sum_{i=1}^{n}\left(\frac{\sigma_{i}}{\sigma_{0}}\right)^{m} \Delta V_{i}}, \sigma_{i}>0
$$

Note to the Weibull's modulus $m$ : The modulus expresses the measure of dispersion of the ceramic material strength. It is defined as a slope of the regression line in Fig. 4 for real 3-point bending experiments $\left(h=b=2,5 \mathrm{~mm}, L_{1}=10 \mathrm{~mm}, L_{2}=0 \mathrm{~mm}\right)$ [14]:

$$
\begin{aligned}
& \ln \left(\ln \frac{1}{1-P_{f}}\right) \\
& M O R=\frac{3\left(L_{1}-L_{2}\right) F}{2 h^{2} b} .
\end{aligned}
$$

The MOR (Modulus of Rupture) quantity is the maximum flexural stress under which destruction occurs in four-point bending (Fig. 4). Measuring to determine $m$ is realized on many samples (at least 35). Method of $P_{f}$ probability determination is shown e.g. in [6].

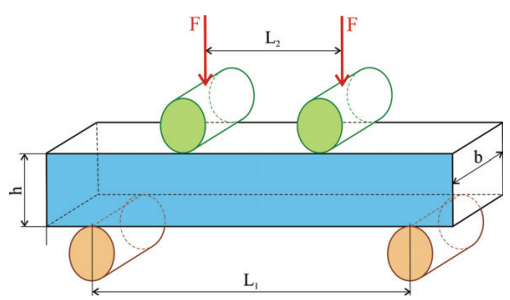

Fig. 3 Modulus of rupture test dimensions

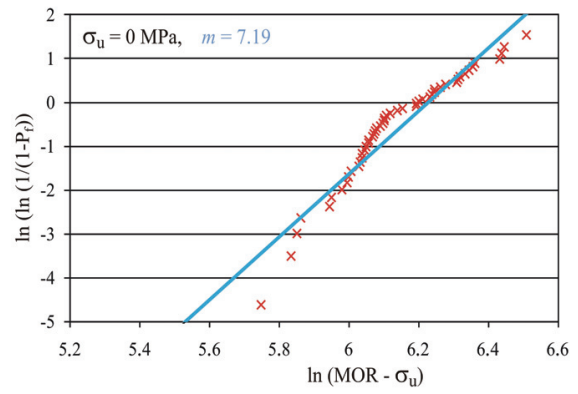

Fig. 4 Weibull plot of the normalized MOR data [14] 
B. Weibull's model of destruction probability for a 3-axis general stress

Apart from the aforementioned two and threeparametric analysis of ceramics destruction probability for 1-axis stress, Weibull also designed a modification of destruction probability valid for general spatial (three-axis) stress. He proceeded from the hypothesis that in spherical pores in ceramics, maximum stress around the pore is independent of its size [1]. He also assumed that destruction of ceramics is caused by a combination of normal stress $\sigma_{n}$ (impacting fractures perpendicularly and resulting in the $1^{\text {st }}$ fracture mode) and maximum shear stress $\tau$ (acting in the fracture plane and resulting in $2^{\text {nd }}$ fracture mode). Both these stresses are the functions of principal stresses $\sigma_{1}, \sigma_{2}, \sigma_{3}$. This is standard approach for many physical conditions. Since we are dealing with a spherical pore, the stress $\sigma_{n}$ and $\tau$ on the surface of a sphere with unit radius [1] (Fig. 4) is determined as follows:

$\sigma_{n}=\cos ^{2} \Phi\left(\sigma_{1} \cos ^{2} \Psi+\sigma_{2} \sin ^{2} \Psi\right)+$

$+\sigma_{3} \sin ^{2} \Phi$

$$
\tau=\sqrt{\begin{array}{l}
\cos ^{2} \Phi\left(\sigma_{1}^{2} \cos ^{2} \Psi+\sigma_{2}^{2} \sin ^{2} \Psi\right)+ \\
+\sigma_{3} \sin ^{2} \Phi-\sigma_{n}^{2}
\end{array} .}
$$

$\Psi$ angle between the projection of stress $\sigma_{n}$ into $\left(\sigma_{1}, \sigma_{2}\right)$ plane with $\sigma_{1}$ direction (Fig. 5)

$\square$ angle between the plane $\left(\sigma_{1}, \sigma_{2}\right)$ and the stress $\sigma_{n}$ direction (Fig. 5)

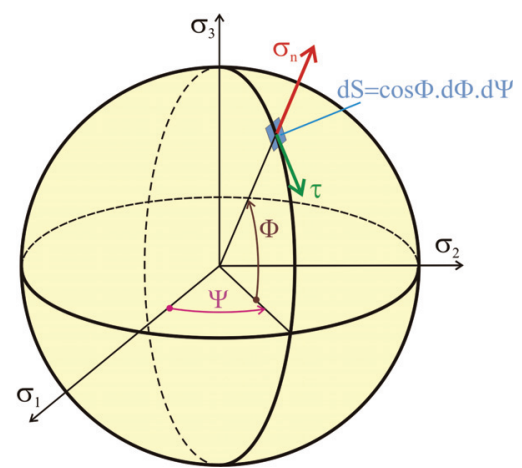

Fig. 5 Unit radius sphere representing all possible flaw/crack orientations
In the final version proposed by Weibull to analyze ceramics destruction probability, he neglected the impact of shear stress on the destruction [21]. Yet the aforementioned method is used frequently. He proposed the following formula to respect the impact of general spatial stress on the probability of destruction:

$P_{f}=1-e^{\left\{-\int_{V}\left[k \int_{S}\left(\sigma_{n}\right)^{m} d S\right] d V\right\}}$,

where

$d S$ elementary facet on the sphere with unit radius: $d S=\cos \Phi \cdot d \Phi \cdot d \Psi$,

$k$ the so-called scale factor, defined as follows:

$$
k=\frac{2 m+1}{2 \pi \sigma_{0}^{m}}
$$

After substituting formulae we get the final equation (6) which is written on the bottom of this page.

\section{Comparative analyses of Weibull's model for 1-axis and 3-axis stress}

Comparative analyses were carried out for the following material characteristics: Weibull's modulus $m=7,19$ (Fig. 3), normalized material sthrength of material volume unit $\sigma_{0}=473,8\left[\mathrm{MPa} \cdot \mathrm{m}^{3 / 7.19}\right.$ ] [14]. Determination of destruction probability according to Weibull's formulae (1), (2) or (6) always requires integration via a corresponding body. For Weibull's model for 3-axis stress, it is integration in the relation (6), which is time-consuming with the current algorithms. To simplify the testing we

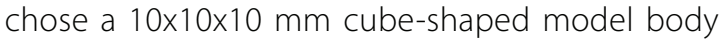
(Fig. 6 - 8). We analyzed the following three stress variants (with different first principal stresses [19]):

1.variant: first principal stress $\sigma_{1}=100 \mathrm{MPa}$, another principal stresses $\sigma_{2}$ and $\sigma_{3}$ are taken the value $(-100 \mathrm{MPa}$ to $+100 \mathrm{MPa})$ - Fig. 6 ,

2.variant: first principal stress $\sigma_{1}=150 \mathrm{MPa}$, another principal stresses $\sigma_{2}$ and $\sigma_{3}$ are taken the value (-150MPa to +150MPa) - Fig. 7 ,

3.variant: first principal stress $\sigma_{1}=200 \mathrm{MPa}$, another principal stresses $\sigma_{2}$ and $\sigma_{3}$ are taken the value (-200MPa to +200MPa) - Fig. 8.

This covered all types of stresses: 3 -axis general $\left(\sigma_{1}\right.$ $\left.\neq \sigma_{2} \neq \sigma_{3} \neq 0\right)$, 3 -axis semi-even $\left(\sigma_{1}=\sigma_{2} \neq \sigma_{3} \neq 0\right)$ 3-axis

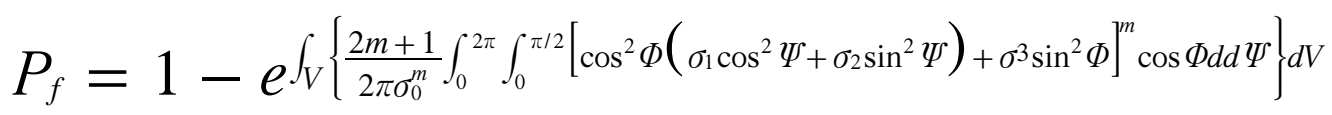


even tensile $\left(\sigma_{1}=\sigma_{2}=\sigma_{3} \neq 0\right)$ 2-axis general $\left(\sigma_{1} \neq \sigma_{2} \neq\right.$ $\left.0, \sigma_{3}=0\right)$, 2-axis even tensile $\left(\sigma_{1}=\sigma_{2} \neq 0, \sigma_{3}=0\right)$, shear $\left(\sigma_{1} \neq 0, \sigma_{3}=-\sigma_{1}, \sigma_{2}=0\right)$ that were homogenous in the entire cube.

Owing to identical volumes and homogenous stress in all cube elements it sufficed to determine destruction probability in a single element and its multiplication by the total number of cube elements gave us the destruction probability for the entire cube. We created our own computation algorithm for the aforementioned process using the Maple software.

Dependences of destruction probability of the model cube on stresses $\sigma_{1}, \sigma_{2}, \sigma_{3}$ for $1^{\text {st }}$ to $3^{\text {rd }}$ version (i.e. for Weibull's 3-axis stress model) are shown in Fig. 6 - 8. These graphs also show dependence of model cube destruction probability for the twoparameter model for 1-axis stress, i.e. for the first principal tensile stress (2).

Fig. 6 - 8 reveal that the second and third stresses substantially affect destruction probability in three-axis stress when all three principal stresses are tensile (positive).

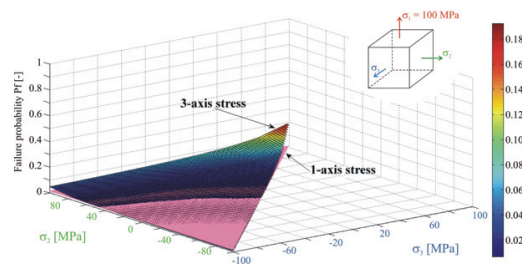

Fig. 6 Surfaces of failure probability in Weibull's model for 3-axis stress $\left(\sigma_{1}=100 \mathrm{MPa}\right)[19]$

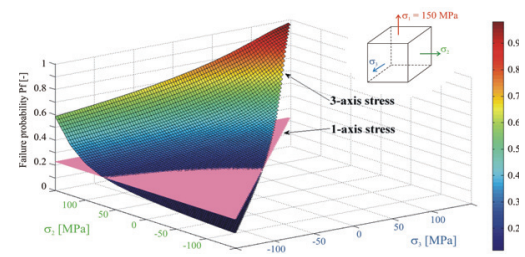

Fig. 7 Surfaces of failure probability in Weibull's model for 3-axis stress $\left(\sigma_{1}=150 \mathrm{MPa}\right)[19]$

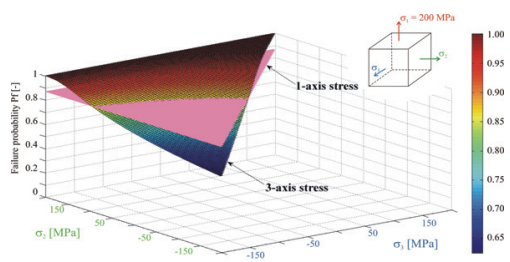

Fig. 8 Surfaces of failure probability in Weibull's model for 3-axis stress $\left(\sigma_{1}=200 \mathrm{MPa}\right)[19]$

\section{Impact of macro-deviations of taper contact surface ge- ometry, such as differing taper ratio and ovality, on the stress in ceramic heads}

It is obvious that computational modeling of destruction probability in the heads must be preceded by computational modeling of stress conditions in the heads.

Stress and subsequent destruction probability in the heads has been investigated for various stressing methods. First, it was computational modeling simulating static tests of the head strength according to ISO 7206-5 [17] as shown in Fig. 9 (the stressing force acts in the axis of the ceramic head and steel stem), followed by stress calculations simulating stressing of the heads corresponding to physiological conditions in a person standing on one leg, and finally calculations simulating a walking man. This report only quotes the results of the first case.
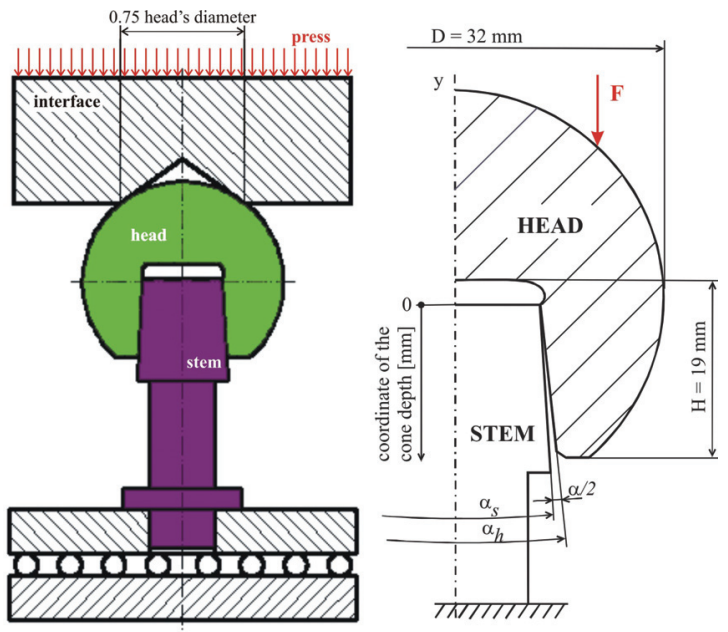

Fig. 9 Scheme of the testing device for static tests of the head strength according to ISO 7206-5

Deformation-stress states in the heads were determined by the method of finite elements, using the ANSYS software. Dimensions of the system components and discretization of a part of the head and stem is shown in Fig. $9-10$.

We first determined stress (in each head point we determined three principal stresses and directions thereof) in case the top angle of the head (angle $\alpha_{\mathrm{h}}$ - Fig. 9 and 11) and the top angle of the stem (angle $\alpha_{\mathrm{s}}$ ) are identical and there exists perfect circularity (i.e. there is no ovality of individual imaginary cross-sections along the taper height perpendicu- 
lar to the taper axis) [10]. It was a sort of "standard stress" with which we compared the calculation results considering geometric imperfections. In the text below, the results of this "standard" are referred to as VAR 0 .
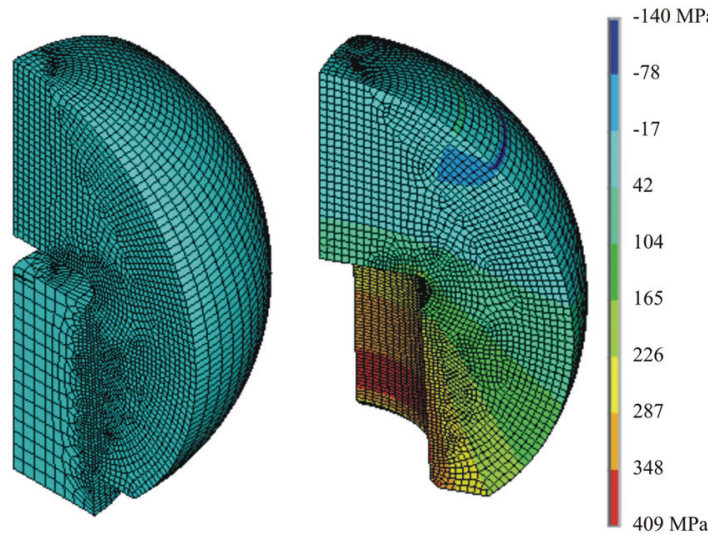

Fig. 10 System discretization and the first principal stress distribution in the head for VAR 0

Then we did calculations for macro-parameters of shape imperfections for various taper ratios (defined by tilt angles of surfaces on the taper stem and head) and various ovality (circularity in various taper heights) [2], [7], [8]. See the results for two extreme instances (Fig. 11). In the first instance (VAR 1 - Fig. 12 green colour), the top stem angle $\alpha_{\mathrm{s}}$ is larger than the top angle $\alpha_{\mathrm{h}}$ and thus the taper of the stem and the taper of the head initially touched around point A (Fig. 11). In the second instance (VAR 2 - Fig. 12 red colour), the angles are opposite $\left(\alpha_{\mathrm{s}}<\alpha_{\mathrm{h}}\right)$, so the tapers first touch around point B. Schematic of model ovality (VAR 3) with the gap value $0,01 \mathrm{~mm}$ is shown in Fig. 12.
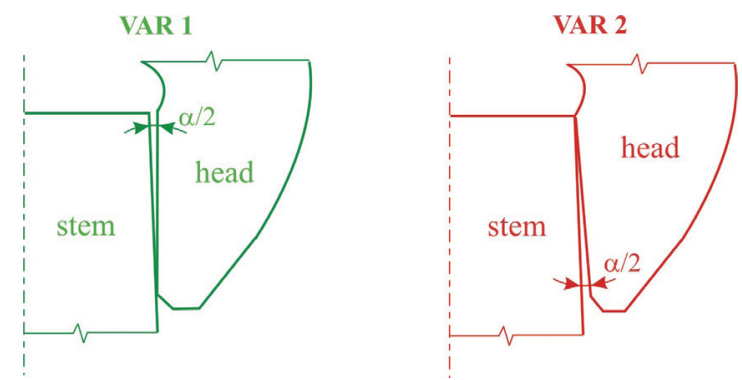

Fig. 11 Assumed extreme cases of model taper ratios

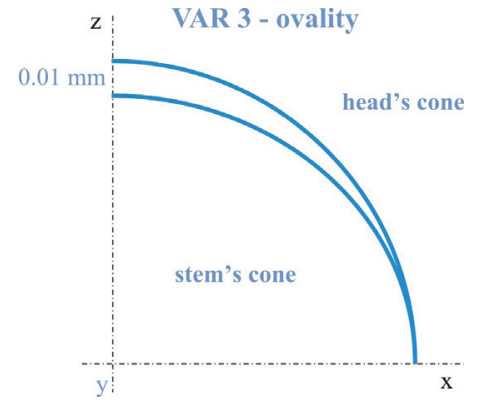

Fig. 12 Scheme of model ovality

Results of computational analyses have shown that in the variants VAR 0 and VAR 1, the largest positive stresses (the first principal stresses) are the peripheral (hoop) stress in the area A (Fig. 11). In the variant VAR 2, the location of maximum peripheral stress moved to area B [9]. Values of maximum peripheral stresses in the area A can be seen in Fig. 13.

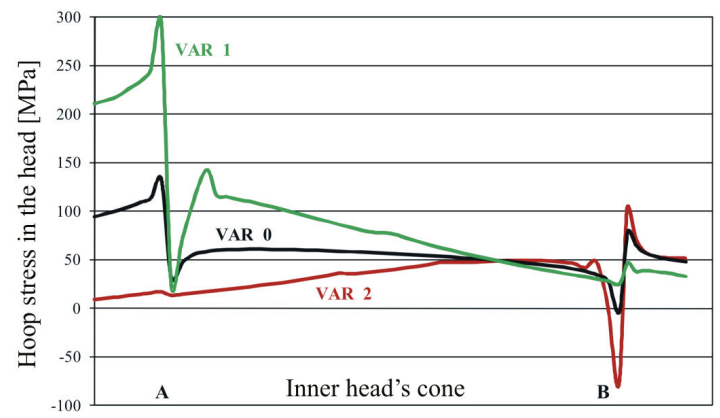

Fig. 13 Influence of hoop (peripheral) stresses along the height of the internal taper of the head

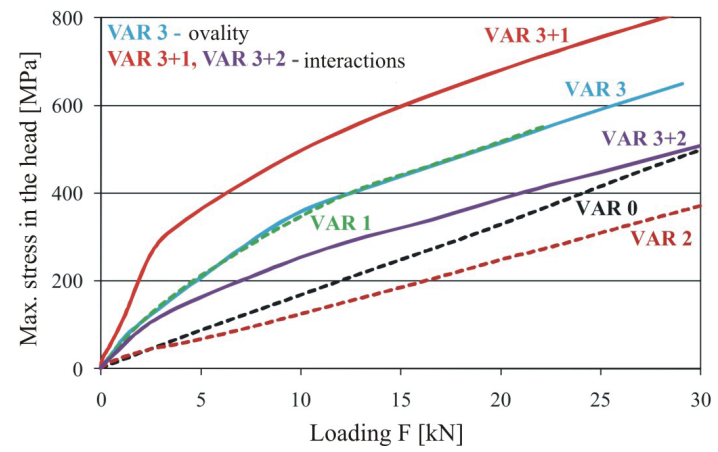

Fig. 14 Influence of maximal stresses during the loading for all assumed variants

The following results can be drawn from the behavior of the stress in Figs. 13 - 14:

With the taper ratios where the head first contacts the stem in the area A (i.e. VAR 1), the values 
of maximum peripheral stresses are much higher than in the variant VAR $O$ (maximum stress along the entire perimeter). Therefore in variant VAR 1 there is higher head destruction probability than in VAR 0.

Ovality (VAR 3) causes local increase in maximum peripheral stress (in one are along the perimeter) on the same level as variant VAR 1. - Interaction of shape imperfections (VAR 1+3, $V A R 2+3)$ increases tensile stress in the head.

The aforementioned statements lead to the following recommendations:

Do not allow manufacturing tolerances leading to VAR 1.

- Minimize ovality.

After the introduction of these recommendations into manufacturing of ceramic heads and metal stems, the rate of head fractures in total joint endoprostheses in clinical practice dropped to statistically insignificant minimum.

\section{Impact of macro-deviations in taper geometry, such as taper ratio and ovality, on destruction probability in ceramic heads}

It this way we defined dependences of destruction probability on the rate of stress on the head (the so-called S-curve) for macroscopic shape deviations in the taper connection (taper ratio and ovality). Fig. 15 clearly shows that macroscopic deviations of type VAR 1, VAR 3 and their interactions decrease stress rates in the head that cause fractures (curves of destruction probability for micro-roughness moves to the left from the curve for the variant VAR 0). Results of the analyses of head destruction probability may differ from stress analyses, because the destruction probability calculation counts, apart from individual stresses, also with the volume in which the stress acts. You can see this in Fig. 14, where maximum stress in heads for VAR 1 and VAR 3 is identical, and Fig. 15, where the head destruction probability for the two variants differs. The specific cause lies in the fact that in the axis symmetric variant (VAR 1), maximum stresses occur in a larger volume (along the entire head perimeter) than in VAR 3 (only in the volume around the head/stem contact).

Although the acquired resulting values of head destruction probabilities may be burdened with some systemic errors, the "trends" shown by these probabilities are not affected. And acquiring and understanding of trends is the most important thing.

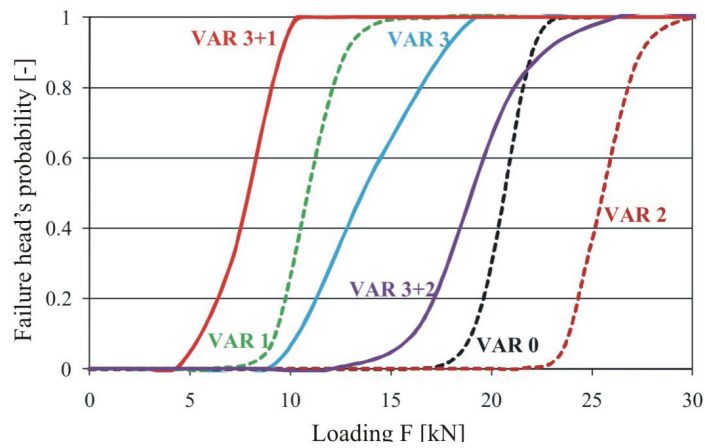

Fig. 15 Curves of head's failure probability for various variants and combinations thereof

\section{Impact of local micro-roughness on taper surfaces on the head destruction probability}

For reliability assessment of ceramic heads regarding fragile destruction it is essential to possess knowledge of how surface micro-roughness of taper and stem caused by splinter machining of taper surfaces affect the values of ceramic head destruction probability. Illustration of measured micro shape deviations on the stem and head from ideal taper shape (micro-roughness) on the expanded tapers of stem and head are in Fig. 16 [11]. We may state that in this instance the microroughness values are $\pm 3,5 \mu \mathrm{m}$. The established data on micro-roughness helped us answer the following question: what will be the range of ceramic head destruction probability depending on stress if the stem and head are mutually positioned (turned)? The question describes the fact that the orthopedist puts the head on the stem randomly [13]. The aforementioned question was answered by computational modeling of deformation-stress conditions and calculations of destruction probability according to Weibull (the applied two-parameter variant and assuming only 1-axis stress) [12].

We realized the computational series for individual mutual positions of stem and head (mutually positioned by $18^{\circ}$ steps, Fig. 17). Results of the head destruction probability calculations are in Fig. 18. We may state that the impact micro-roughness manifests itself in a certain range of probability. Fig. 18 shows variant VAR 2 with zero micro-roughness and nominal values of tapers $\sigma_{\mathrm{h}}=5^{\circ} 46^{\prime} 44^{\prime \prime}$ and $\sigma_{\mathrm{s}}$ $=5^{\circ} 39^{\prime} 24^{\prime \prime}$. The range of probability for non-zero 
deviations is shifted to the left from the VAR2 curve, i.e. towards lower stress. We may thus observe that micro-roughness substantially impacts the reliability of ceramic heads.
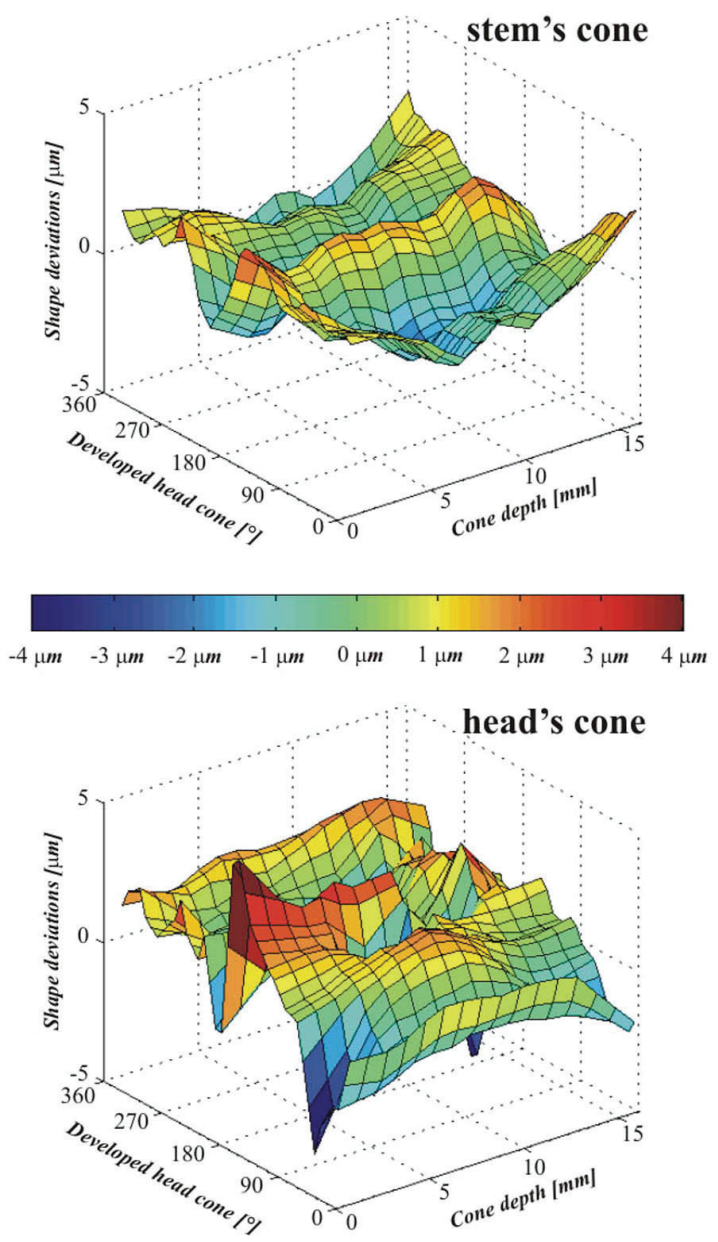

Fig. 16 Illustration of experimentally measured micro shape deviations from ideal taper

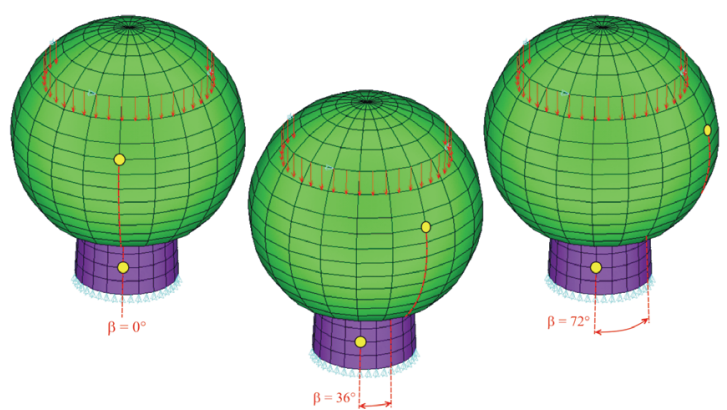

Fig. 17 Simulation of the random position head on the stem cone

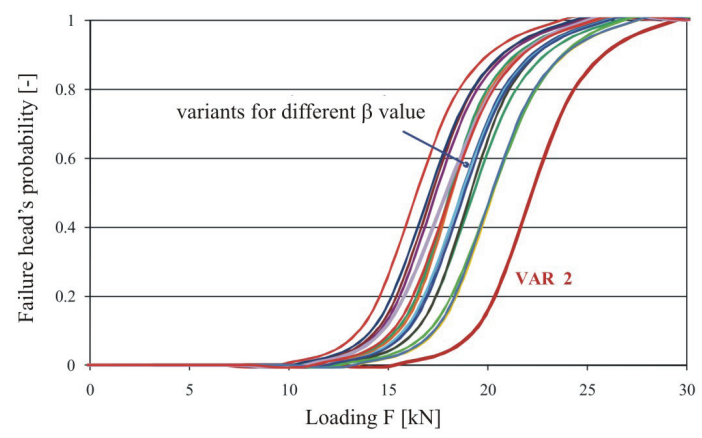

Fig. 18 Head failure probability curves for stochastic distribution of micro-roughness on the head and stem taper surfaces (various $\beta$ angle values).

\section{ACKNOWLEDGEMENT}

This paper was prepared with the suport of the following projects AV0Z20760514 and MSM0021630518.

\section{CONCLUSION}

Computational modeling has shown that the character and size of shape deviations on the taper contact surface between the stem and head of hip endoprosthesis is substantially affected by the character and amount of stress in the head and thus the value of it coherence destruction probability. Ignorance of this impact may lead to unforeseen fractures of ceramic heads and thus affect the trust in certain types of endoprosthesis as well as the trust the surgery has been carried out properly. Theoretically, micro-roughness caused by splinter machining plays a major role as well. However, practically, micro-roughness on a metal stem may "dampen" stress concentrations from macroimperfections by being able to plasticize. Verification of this hypothesis is demanding because it requires solving of deformation-stress conditions of stems in elastic-plastic condition.

\section{REFERENCES}

[1] Andreasen, J.H., Reliability-based design of ceramics. Materials and Design. Vol. 15, Nr. 1, 1994, pp. 3-13

[2] Andrisano, A. O., Dragoni, E., Strozzi, A., Axisymmetric mechanical analysis of ceramic heads for total hip replacement. Proc. Inst. Mech. Engrs, Part H, Vol. 204, 1990, pp. 157-167

[3] Bergmann, G., Graichen, F., Rohlmann, A., Hip joint loading during walking and running 
mesured in two patients. Journal of Biomechanics, Vol. 26, No. 8, 1993, pp. 969-990

[4] Bergmann, G., Kniggendorf, H., Graichen, F. Rohlmann, A., Influence of shoes and heel strike on the loading of the hip joint. Journal of Biomechanics, Vol. 28, No. 7, 1995, pp. 817827.

[5] Beznoska S., Čech O., Löbl, K., Artificial substitution of human joints. Biomechanical, material and technological aspects. First edition, SNTL Prague, 1987, (in Czech)

[6] Bush, D.R., Designing ceramic components for structural applications. Journal of Materials Engineering and Performance. Vol. 2 (6), 1993, p. 851-862

[7] Dragoni, E., Andrisano, A. O., Structural evaluation of ceramic femoral heads: Effect of taper, friction, support conditions and trunnion compliance. Journal of Biomechanical Engineering, Vol. 117, 1995, pp. 293-299

[8] Fuis V., Stress and reliability analyses of ceramic femoral heads with 3D manufacturing inaccuracies. 11th World Congress in Mechanism and Machine Science, Vols. 1-5, Tianjin, Peoples R China, 2004, pp. 2197-2201

[9] Fuis V., Janíček P., Stress and reliability analyses of ceramic femoral heads with axisymmetric production inaccuracies. IFMBE Proc. Vol. 1 part 1 and 2, MEDICON 2001, Pula, Croatia, 2001, pp. 632-635

[10] Fuis V., Janíček P., Stress and reliability analyses of damaged ceramic femoral heads. Damage \& Fracture Mechanics VII. WIT Press, 2002, pp. 475-486

[11] Fuis V., Janicek P., Houfek L., Stress and reliability analyses of the hip joint endoprosthesis ceramic head with macro and micro shape deviations. IFMBE Proc. Vol. 23, ICBME, Singapore, 2008, pp. 1580-1583

[12] Fuis V., Navrat T., Hlavon P., et al.. Reliability of the ceramic head of the total hip joint endoprosthesis using Weibull's weakest-link theory. IFMBE Proc. Vol. 14, Congress on Medical Physics and Biomedical Engineering, Seoul, South Korea, 2006, pp. 2941-2944

[13] Fuis V., Návrat T., Stress analysis of the hip joint endoprosthesis with shape deflections, Engineering Mechanics, Vol. 12, Nr. 5, 2005, pp. 323-330

[14] Fuis, V., Stress and reliability analyses of the ce- ramic head of hip point endoprosthesis, Ph.D work, Brno University of Technology, Faculty of Mechanical Engineering, 1999, 161 pages, (in (zech)

[15] Fuis, V., Janíček, P., Behaviour of the hip joint endoprosthesis ceramic head with manufacturing inaccuracies under ISO 7206-5 loading. Engineering Mechanics, Vol. 10, No. 5, 2003, pp. 399-411

[16] Hastings, J. G., Handbook of biomaterial properties. 1st ed.London, Chapman \& Hall, 1998, p. 573

[17] ISO 7206-5, Implants for surgery - Partial and total hip joint prostheses. Determination of resistance to static load of head and neck region of stemmed femoral components, 1992

[18] Janíček, P., Systematic approach to selected topics for technicians - seeking for relationships. CERM, VUTIUM, Brno, 1234 pages, 2007, (in Czech)

[19] Málek, M., Reliability analysis of the hip point endoprosthesis ceramic head. Diploma work, Brno University of Technology, Faculty of Mechanical Engineering, 2010, 75 pages, (in (zech).

[20] McLean A. F., Hartsock D. L., Engineered materials handbook, Vol. 4, Ceramics and Glasses. ASM International 1991, 676-689

[21] Weibull, W., A statistical theory of the strength of material. R. Swedish Acad. Eng. Sci. Proc., No. 151,1939 , pp. 1-45

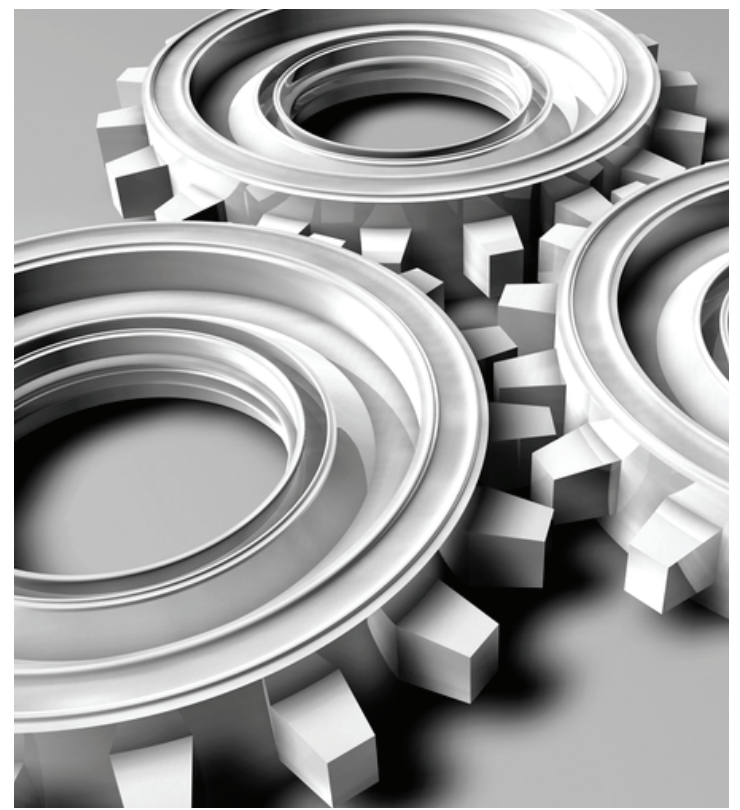

